\title{
OS DESAFIOS DA URBANIZAÇÃO PARA A EDUCAÇÃO EM SAÜDE
}

"Put your tents apart to bring your hearts closer together"

(Provérbio Árabe)

Krausz, R. R. - Os desafios da urbanização para a educação em saúde. Rev. Saúde públ., S. Paulo, 5:285-9, 1971.

Resumo - Os grandes centros urbanos, em virtude de seu rápido crescimento, contribuem para acentuar a problemática da saúde. Na cidade de São Paulo observa-se a "existência de uma precária condição de saúde quando se analisa os indicadores globais pertinentes. Daí a importância que assume a Educação em Saúde como forma de alterar os padrões de comportamento do consumidor dos serviços de saúde, conscientizando-o e fazendo com que participe ativamente nos programas desta área. Trata-se de um vasto campo de ação que exige a presença do Educador de Saúde trabalhando em estreita colaboração com os outros profissionais.

UNitermos - Urbanização (São Paulo, Brasil) *; Educação sanitária *.

O século XX marcou a história da humanidade como o período da urbanização (2). "Dificilmente será possível apon. tar para qualquer parte ou região do mundo que não enfrente, em maior ou menor grau, as mudanças consideráveis nos padrões de vida e de organização resultantes do crescimento, não apenas de suas cidades, mas também de suas zonas crescentes de influência urbana" 2 .

Este crescimento acelerado é feito em função do crescimento vegetativo da população e dos movimentos migratórios que se fazem da zona rural para a urbana, em particular nos países em desenvolvimento, onde as cidades "incham" sem absorver parte da população que permanece subempregada ou desempregada, sem acesso aos benefícios urbanos como educação, saúde, saneamento do meio ambiente etc. Em conseqüência de um aumento cons. tante da demanda de tais serviços, que não crescem com a mesma rapidez dos seus consumidores, instala-se a "deterioração da qualidade da vida urbana para a maioria dos habitantes" ${ }^{13}$, proliferando a "cultura da pobreza" "que transpóe para o meio urbano muitos traços da zona rural, particularmente na área das

Recebido para publicação em 16-8-1971.

(1) Da Disciplina de Educação em Saúde Pública da Faculdade de Saúde Pública da USP. Av. Dr. Arnaldo, 715, São Paulo, SP - Brasil.

(2) Entendemos por urbanização "a proporçáo da população total que vive em cidades ou áreas urbanas dentro de uma unidade específica". HAUSER * 
KRAUSZ, R. R. - Os desafios da urbanizacāo para a educação em saúde. Rev. Saúde públ., S. Paulo, 5:285-9, 1971.

práticas de saúde, constituindo um "fator dinâmico que afeta a participação na cultura nacional mais ampla e cria uma subcultura própria" ${ }^{12}$.

O fenômeno de urbanização no Brasil segue, em linhas gerais, o modêlo acima descrito, tendo sofrido nos últimos anos um incremento notável como indicam os dados da Tabela 1.

T A BEL A 1

População total e urbana no Brasil de 1940 a 1970

\begin{tabular}{c|c|c|c}
\hline Anos & $\begin{array}{c}\text { População } \\
\text { total }\end{array}$ & $\begin{array}{c}\text { População } \\
\text { urbana }\end{array}$ & $\begin{array}{c}\text { \% da popu- } \\
\text { lação urba- } \\
\text { na sôbre } \\
\text { total da } \\
\text { população }\end{array}$ \\
\hline 1940 & 41.089 .553 & 12.864 .509 & $\mathbf{3 1 , 3 0}$ \\
1950 & 51.576 .461 & 18.721 .078 & 36,29 \\
1960 & 70.967 .185 & $\mathbf{3 1 . 9 9 0 . 9 3 8}$ & $\mathbf{4 5 , 0 7}$ \\
1970 & $\mathbf{9 4 . 5 0 8 . 5 5 4 ^ { * }}$ & $\mathbf{5 2 . 9 0 4 . 7 4 4 ^ { * }}$ & $\mathbf{5 5 , 9 8}$
\end{tabular}

FONTE: Anuário Estatistico do Brasil.

* Informacões obtidas na Fundacão IBGE.

Este crescimento é denominado "urbanização sociopática" e é um "traço marcan. te das sociedades latino-americanas nas últimas décadas" ${ }^{10}$, por não corresponder a um aumento propocional das oportunidades de emprêgo, produzidas pelo processo de industrialização e conseqüente aumento do setor de serviços urbanos. Resulta daí que apenas parte da população urbana brasileira usufrui de melhores condições de trabalho, do sistema educacional, dos serviços das agências de saúde, de habitações adequadas, enfim, daqueles traços que caracterizam o estilo de vida urbano. Isto nos leva a concluir que, apesar do desenvolvimento tecnológico, o homem ainda não encontrou respostas satisfatórias para os problemas das grandes cidades, entre os quais podemos citar a superpopulação, congestionamento de cons- truções, proliferação de cortiços e favelas, lixo, poluição do ar, da água, ruído, acidentes automobilísticos, que contribuem para aumentar a problemática da saúde no meio urbano ${ }^{8}$.

A cidade de São Paulo - A capital paulista constitui um caso extremo de urbanização. As Tabelas 2 e 3 revelam uma explosão populacional sem precedentes, responsável pelos problemas, cuja eclosão desafia administradores, educadores, sanitaristas e planejadores.

TABEL A 2

Caracteristicas gerais do crescimento da população do município de São Paulo.

\begin{tabular}{l|c|c|c|c}
\hline \multirow{2}{*}{ Ano } & $\begin{array}{c}\text { Popu- } \\
\text { lação }\end{array}$ & \multicolumn{4}{|c}{ Incremento } \\
\cline { 3 - 5 } & Total & $\begin{array}{c}\text { Vegeta- } \\
\text { tivo }\end{array}$ & $\begin{array}{c}\text { Migra- } \\
\text { tório }\end{array}$ \\
\hline 1940 & 1.326 .261 & & & \\
$195 \%$ & 2.198 .096 & 871.835 & 210.255 & 661.580 \\
1960 & 3.788 .857 & 1.590 .761 & 613.261 & 977.500 \\
1970 & 5.901 .533 & 2.112 .676 & 885.196 & 1.227 .480 \\
\hline
\end{tabular}

FONTE: Recursos humanos da Grande São Paulo 11, p. 63.

T A B E L A 3

Taxas de incremento intercensitário.

\begin{tabular}{c|c|c|c}
\hline $\begin{array}{c}\text { Periodo consi- } \\
\text { derado }\end{array}$ & \multicolumn{3}{|c}{ Incremento } \\
\cline { 2 - 2 } & Total & $\begin{array}{c}\text { Vegeta- } \\
\text { tivo }\end{array}$ & $\begin{array}{c}\text { Migra- } \\
\text { tório }\end{array}$ \\
\hline
\end{tabular}

1940/50 Decenal $65,8 \% \quad 15,8 \% \quad 50,0 \%$

\begin{tabular}{rrrr} 
Anual & $\mathbf{5 , 2 0} \%$ & $\mathbf{1 , 4 8 \%}$ & $\mathbf{4 , 1 4 \%}$ \\
\hline $\mathbf{1 9 5 0 / 6 0}$ Decenal & $\mathbf{7 2 , 4} \%$ & $\mathbf{2 7 , 9} \%$ & $\mathbf{4 4 , 5} \%$ \\
Anual & $\mathbf{5 , 6 0 \%}$ & $\mathbf{2 , 4 9 \%}$ & $\mathbf{3 , 7 6 \%}$ \\
\hline $1960 / 70$ Decenal & $\mathbf{5 5 , 8} \%$ & $\mathbf{2 3 , 4} \%$ & $\mathbf{3 2 , 4} \%$ \\
Anual & $\mathbf{4 , 5 4 \%}$ & $\mathbf{2 , 1 3} \%$ & $\mathbf{2 , 8 5} \%$
\end{tabular}

FONTE: Recursos humanos da Grande Săo Paulo 11, p. 63. 
KRAUSZ, R. R. - Os desafios da urbanização para a educacão em saúde. Rev. Saúde públ., S. Paulo, 5:285-9, 1971.

Um indicador da amplitude dos problemas da capital paulista é constituído pelas "condições reais" de saúde da sua população. YUNES ${ }^{14}$, toma como indicadores globais de saúde a vida média e a mortalidade geral e como indicador específico de saúde a mortalidade infantil. Com base nestes instrumentos de análise conclui que: 1. Os níveis de mortalidade geral refletem "a existência de uma precária condição de saúde", mantendo o Município o mesmo valor observado para o Interior e para o Estado. 2. A vida média do habitante paulistano ${ }^{(1)}$ coloca o Município em "estágio intermediário no desenvolvimento de saúde pública". 3. A mortalidade infantil, que é um "indicador seguro para o diagnóstico das condições de saúde" mostra uma situação bastante desfavorável (Tabela 4).

TA B E L A 4

Mortalidade infantil na Capital Paulista Taxas brutas de mortalidade

\begin{tabular}{l|r}
\hline Ano & $\begin{array}{r}\text { Mortalidade infantil (p. } 1.000 \\
\text { nascidos vivos) }\end{array}$ \\
\hline 1940 & 123,99 \\
1950 & 89,71 \\
1960 & 62,94 \\
1961 & 60,21 \\
1963 & 69,90 \\
1965 & 69,38 \\
1967 & 74,31 \\
1969 & 83,00 \\
\hline
\end{tabular}

FONTE: Recursos humanos da Grande São Pauto", p. 74.

São Paulo e Seus Problemas de Saúde A capital paulista, a maior cidade brasileira, tem níveis de saúde que pouco diferem dos níveis do interior do Estado, estando sujeitos a uma deterioração, como indicam as taxas de mortalidade infantil. Isto nos leva a crer que São Paulo está acumulando problemas de saúde típicos das grandes aglomerações urbanas com outros, ainda não convenientemente resolvidos, de origem rural.

Sem nos determos nos aspectos fundamentais da infra-estrutura sanitária urbana, cuja importância é por demais conhecida pelos especialistas em saúde pública, parece-nos básico analisar a questão saúde a partir da "compreensão do meio urbano e de seu efeito sôbre o habitante da cidade, como indivíduo, em sua vizinhança, em seu local de trabalho, ou em qualquer das situaçōes especiais que compõem o meio urbano" $"$.

Os níveis de saúde de qualquer aglomerado urbano estão em função dos padrōes de comportamento de seus habitantes. Qualquer intervenção que vise uma mudança só terá sucesso na medida em que levar em consideração o componente humano do problema em causa. A mera presença de recursos profissionais, materiais ou financeiros não assegurará melhores níveis de saúde se a população, que se pretende assistir, não fôr preparada para usá-los convenientemente. Existem na história da saúde pública no Brasil, muitos casos que ilustram esta afirmação. Bastaria citar a incidência de varíola no território brasileiro. Em 1968, dos 4.375 casos notificados de varíola na América do Sul, 4.372 foram pelo Brasil ${ }^{9}$. Esta preparação só será alcançada nas diferentes camadas sociais, na medida em que fôr integrada aos padrōes culturais urbanos, transformandose em "universais" da cultura urbana ${ }^{7}$, e isto pressupõe a difusão de informações e a mudança de comportamento relacionadas com os conceitos de saúde e doença.

E nesta perspectiva que se coloca o objetivo da Educação em Saúde, da forma em que foi definida pela Organização Mundial da Saúde:

"A Educação em Saúde ajuda as pessoas, individualmente ou em grupo, a desenvolver seu desejo de saúde, a conscientizar seus problemas de saúde pessoais, particulares, profissionais e sociais, a absorver o conhecimento necessário, e através

(1) Calculada em 60,8 anos para 1962 (YUNeS ${ }^{14} Q$. 
KRAUSZ, R. R. - Os desafios da urbanização para a educação em saúde. Rev. Saúde públ., S. Paulo, 5:285-9, 1971.

do aconselhamento e encorajamento necessários, aprender a forma de aplicar êste conhecimento" "1". Uma definição mais sucinta da própria OMS indica como objetivo da Educação em Saúde "ajudar as pessoas a conseguirem saúde através de sua própria ação e esforços" ".

$\mathrm{Na}$ realidade urbano-industrial paulistana êste objetivo parece inatingível a curto prazo, considerando que uma porcentagem grande dos moradores da metrópole situam-se apenas perifèricamente no contexto urbano e que a participação em atividades de caráter comunitário é ainda muito acanhada. Tal afirmação fundamenta-se na pequena expressividade da participação dos moradores dos bairros periféricos da capital, onde os problemas de saúde são consideráveis, nas Sociedades Amigos de Bairros. Uma pesquisa realizada em 1969 revela que apenas $3,11 \%$ da população estudada participara de Sociedades Amigos de Bairro.

Ora, a Educação em Saúde, além de informar o consumidor dos serviços de saúde, propõe-se a fazê-lo participar ativamente nos programas de saúde "numa tentativa de ultrapassar a brecha existente entre o conhecimento de saúde que se expande ràpidamente e as práticas de saúde" 1". No caso de São Paulo, isto envolve a mudança de padrões de comportamento bastante arraigados e onde o quadro de referência tem, tradicionalmente, sido o indivíduo em detrimento dos interêsses da comunidade. Aliäs, as próprias condições da vida urbana, que afrouxam os canais de identificação do indivíduo com o grupo, tendem a acentuar o individualismo dificultando ainda mais a tarefa que a Educação em Saúde se propõe. Por isso deve esta utilizar todos os canais de comunicação disponíveis para apressar a mudança de atitudes, conhecimentos e práticas de saúde.

O campo de ação, pelo visto, é vasto e inexplorado, os profissionais especializados ainda são poucos, as necessidades crescem constantemente e devem ser atendidas simultâneamente a nível curativo e pre- ventivo, pois, o aumento desordenado da cidade cria problemas de tal ordem que seu contrôle está a exigir medidas de urgência.

Basta atentarmos, por exemplo, para a incidência de doenças transmissiveis, que em 1967 causaram 6,1\% dos óbitos ocorridos na capital. Esta é uma área passível de ser trabalhada com ótimos resulta. dos pela Educação em Saúde.

Impõe-se a formação de um número maior de profissionais especializados nesta área, pois, sem a participação efetiva e constante do Educador de Saúde Pública, as intervenções no campo da saúde pública cairão no imediativismo que não traz soluções definitivas para os problemas em pauta.

Outra medida de resultados multiplicadores é a conscientização de todos os grupos profissionais que trabalham na Saúde Pública, alertando-os para a importância da função de informantes das populaçôes com as quais trabalham. A incapacidade de comunicação efetiva entre profissional e cliente acarreta um prejuízo enorme ao rendimento do trabalho, pois, desperdiça-se uma oportunidade excelente de educar que é o contato direto, face a face, entre médico e paciente, dentista e cliente, por exemplo. Tal falha deve-se ao desconhecimento que o profissional tem da gama de comportamentos, reações, valores e idéias dos seus clientes, e que variam segundo sua origem, classe social, religião, nível de instrução, etc. ${ }^{5}$.

A Educação em Saúde, como área nova de conhecimentos, tem-se enriquecido graças às contribuições nas Ciências Sociais, da Educação e das Ciências Biológicas, contando hoje com um acervo considerável, capaz de contribuir para o aprimo. ramento da Saúde Pública. Faz-se necessária sua integração, a nível de planejamento, de execução e de avaliação, nos programas de saúde, para assegurar que se considere devidamente as características sócio-econômico-culturais dos sêres humanos, expressos através do seu comportamento. 
KrAUSZ, R. R. - Os desafios da urbanização para a educação em saúde. Rev. Saúde públ., S. Paulo, 5:285-9, 1971.

Sem isto o objetivo central é último da ação desencadeada, que é o ser humano, não poderá beneficiar-se dêste esfôrço.

Krausz, R. R. - [The challenges of urbanization for health education]. Rev. Saúde públ., S. Paulo, 5:285-9, 1971.

Summary - Because of their rapid growth, the big urban centers contribute to increase health problems. In the city of São Paulo, one can see "the existence of a precarious health condition" when one analyses its health indicators. This is why Health Education, as a way of changing behavior patterns of the health services consummer, becomes important. It makes him concious of the problems and brings him into active participation in the health program. This is, certainly, a wide field of action which needs the Health Educator working in close association with other professionals.

UNITERMS - Urbanization *; Health education *; São Paulo City, (Brazil)*.

\section{REFERENCIAS BIBLIOGRAFICAS}

1. DOMKE, H. R. \& GUNTHER, J. - The city and the changing. American health system. Amer. J. publ. Hlth., 60:38-44, 1970.

2. HAUSER, P. M. ed - Urbanization in Latin-America. Paris, UNESCO, 1961.

3. INTER-REGIONAL CONFERENCE OF THE PAHO/WHO ON THE POSTGRADUATE PREPARATION OF HEALTH WORKERS FOR HEALTH EDUCATION Philadelphia, 1962. Report. Geneva, World Health Organization, 1964. (Wld Hlth Org. techn. Rep. Ser., 278).
4. KRAUSz, R. R. et al. - Aspiraçōes com relação a programas de educacão de base. São Paulo, Secretaria do Bem-Estar Social da Prefeitura do Município de São Paulo. 1970. [mimeografado].

5. KOOS - The health of regionville. New York, Columbia Univ. Press, 1954.

6. LEWIS, O. - Five families. New York, New American Library, 1965. p. 16.

7. LiNTON, R. - El nombre. México, Fondo de Cultura Económica, 1946.

8. METNEKI, J. - The population implosion. Int. J. Hith. Educ., $7: 120 \sim 4,1964$.

9. ORGANIZACAO PANAMERICANA DA SAUDE - Casos notificados de enfermedades de declaración obrigatoria en las A méricas, 1968. Washington, D.C., 1971. p. 9

10. PEREIRA, L. - Ensaios de sociologia do desenvolvimento. São Paulo, Liv. Pioneira Ed., 1970.

11. RECURSOS Humanos da Grande São Paulo. - São Paulo, Secretaria de Planejamento, 1971. v. 1. [mimeografado].

12. TURNER, C. F. - World progress and problems in health education. Int. $J$. Hith. Educ., 7:106-15, 1964.

13. WestebBe, R. M. - O desafio da urbanização. Rev. Admin. munic., 105:49$50,1971$.

14. YUNES, J. - Os níveis de saúde no município de são Paulo de 1961 a 1967. Rev. Saúde puibl., S. Paulo, 3:41-50, 1969.

15. ZINGENDONK-HOLTWICK, A. - Training: what is the situation. Int. J. Hlth. Educ., 2:177-9, 1959. 